\title{
Impact of radiation dose on local control and survival in extramedullary head and neck plasmacytoma
}

\author{
Michael Oertel ${ }^{1 \dagger}$, Khaled Elsayad ${ }^{1 * \dagger} \mathbb{D}$, Kai Jannes Kroeger ${ }^{1}$, Uwe Haverkamp ${ }^{1}$, Claudia Rudack ${ }^{2}$, Georg Lenz ${ }^{3}$ and
} Hans Theodor Eich ${ }^{1}$

\begin{abstract}
Background: Patients with plasma-cell neoplasia usually suffer from systemic disease, although a minority $(<5 \%)$ may present with solitary involvement of bone or soft tissue (extramedullary plasmacytoma (EMP)). Radiotherapy (RT) is a state-of-the-art treatment for these tumors offering long term curation.

Methods and materials: Between January 2005 and January 2017, twenty-seven patients underwent RT at our institution. The aim of this study was to analyse the effectiveness of various RT doses for different forms of EMP.

Results: A total of 33 radiation courses were administered to 27 patients with a median age of 56 years. The median RT dose was 45 Gy (range: 12-55.8). The local control rate was 76\% (93\% for primary EMP vs. 61\% for the secondary EMP lesions; $P<0.05)$. A complete response $(C R)$ rate to local RT was achieved for $42 \%$ lesions $(67 \%$ for primary EMP vs. $22 \%$ for the secondary EMP lesions; $P<0.01)$. The overall response rate (ORR) for the EMP lesions treated with high-dose regimens ( $>45 \mathrm{~Gy}$ ) versus low-dose regimens ( $\leq 45 \mathrm{~Gy}$ ) was $87 \%$ versus $67 \%$, respectively $(P$ $=0.2)$. The median survival with high-dose RT group was significantly longer $(P=0.02)$. In subgroups analysis, primary EMP patients treated with high-dose RT had a non-significant higher ORR (100\% vs. $80 \%$, respectively; $P=0$. 3 ,) longer duration of LC $(P=0.3)$ with a longer survival $(P=0.05)$ than patients in low-dose group. No significant difference has been detected in secondary EMP patients treated with high-dose RT regarding ORR (60\% vs. 62\%, respectively; $P=1)$, and survival $(P=0.4)$.

Conclusion: RT is an efficacious treatment modality in the treatment of EMP. A radiation dose $\leq 45$ Gy confer a comparable $C R$ rate to high-dose regimens and appears to be an effective treatment for controlling local EMP progression. Radiation dose-escalation may be beneficial for particular subgroups of patients.
\end{abstract}

Keywords: Extramedullary, Plasmocytoma, Radiotherapy, IMRT, Local control, Prognosis

\section{Background}

Plasma cell neoplasms compromise multiple myeloma as well as osseous and extrasosseous plasmocytoma and are defined by the World Health Organisation as diseases with clonal proliferation of heavy chain class-switched mature B-cells with a characteristic secretion of a monoclonal immunglubolin (M-protein) [1]. Isolated accumulations of plasma cell outside the bone are called

\footnotetext{
* Correspondence: Khaled.elsayad@uni-muenster.de

${ }^{\dagger}$ Michael Oertel and Khaled Elsayad contributed equally to this work. ${ }^{1}$ Department of Radiation Oncology, University Hospital of Muenster, Albert-Schweitzer-Campus 1, Building A1, 48149 Muenster, Germany Full list of author information is available at the end of the article
}

extramedullary plamocytoma (EMP) and are predominantly found in the upper aerodigestive tract [1-3]. Other organs may be prone to EMP spread such as skin, lymph nodes, brain, spine, thorax, liver, urogenital and gastrointestinal tract, mammary tissue or extremities [4-12]. Its diagnosis requires a single extramedullary mass of clonal plasma cell with normal bone marrow histology, absence of end organ damages (anemia, hypercalcaemia, renal impairment, osteolysis) and only minimal serum or urine level of monoclonal immunglobuline [1,3]. Literature reviews show typical occurrence between the fourth and seventh decade of life with a male predominance [1, $2,4,13,14]$. Local symptoms in the head-and-neck

(c) The Author(s). 2019 Open Access This article is distributed under the terms of the Creative Commons Attribution 4.0 International License (http://creativecommons.org/licenses/by/4.0/), which permits unrestricted use, distribution, and 
region include epistaxis, facial swelling or facial pain painless mass and visual disturbances as well as sensory or motor cranial nerve impairments $[15,16]$.

Radiotherapy (RT) is the treatment of choice for EMP with high local control rates and long-term curation [3, 17]. As in other hematologic disease, defining the adequate RT dose has taken center stage in the delicate balance between sufficient tumor control and potential toxicity. Whereas dose-deescalation is currently being investigated for lymphoma and leukemia, there is no stringent evidence to suggest low-dose regimes for plasmocytoma [18, 19, 32-34].

In this study we aim to investigate the impact of different radiation dose regime on tumor control and to identify possible prognostic factors.

\section{Methods and materials}

A total of 33 radiation courses were administered to 27 patients (9 females, 18 males) between January 2005 and January 2017 (Table 1). The median age was 56 years (range: 42-86). The median RT dose was 45 Gy (range: 12-55.8). There were fifteen (56\%) patients with primary EMP and twelve (44\%) with secondary manifestations in the head and neck region. The median time interval between the onset of multiple myeloma (MM) and secondary EMP presentation was 43 months (range: 0-109), while only 3 patients (11\%) developed EMP and MM synchronously. All patients underwent head and neck CT scans. Further investigation using MRI or PET-CT was performed in fourteen patients $(42 \%)$. The most common sites were nasal and paranasal sinuses $(N=10$, $30 \%)$, pharyngeal $(N=6,18 \%)$, and cervical soft tissues $(N=6,18 \%)$. Fifteen lesions (45\%) were treated with high RT-doses ( $>45 \mathrm{~Gy}$ ) with a median radiation dose of 50.4 Gy [commonly apllied in patients with nasal/paranasal (60\%) and pharyngeal (83\%) manifestations]. The other eighteen lesions $(55 \%)$ were treated with lower RT-doses up to 45 Gy (median: 33 Gy) in in 12 patients and were commonly applied in patients with orbital $(83 \%)$ and cervical (83\%), and cutaneo-muscular (60\%) manifestations. Fourteen patients $(52 \%)$ received systemic therapies prior or after RT course (11/12 of patients with secondary EMP and $12 / 15$ of patients with primary EMP, $P<.001) .33 \%$ of patients in high-dose RT group received systemic treatment versus $75 \%$ of patients in low-dose group $(P=.054)$. Detailed treatment characteristics are presented in Table 2. Patients with solitary bone lesion have been excluded.

\section{Statistical analysis}

All statistical analyses were conducted with SPSS version 25.0 software (IBM, Armonk, NY). Differences were considered statistically significant at a $P$-value $\leq 0.05$. OS was calculated from the first day of RT. Local control
Table 1 Patient characteristics $(N=27)$

\begin{tabular}{|c|c|c|}
\hline Characteristic & Value & Percentage/range \\
\hline Mean age at EMP Dx, y & $56 y$ & $42-86$ \\
\hline Gender ratio & $18 \mathrm{M}: 9 \mathrm{~F}$ & \\
\hline \multicolumn{3}{|l|}{ Type of EMP } \\
\hline Primary & $15 / 27$ & $56 \%$ \\
\hline Secondary & $12 / 27$ & $44 \%$ \\
\hline \multicolumn{3}{|l|}{ Involved lymph nodes } \\
\hline Yes & $7 / 27$ & $26 \%$ \\
\hline No & $20 / 27$ & $74 \%$ \\
\hline \multicolumn{3}{|l|}{ Bone infiltration/erosion } \\
\hline Yes & $13 / 27$ & $26 \%$ \\
\hline No & $20 / 27$ & $74 \%$ \\
\hline \multicolumn{3}{|l|}{ Immunohistochemical analysis } \\
\hline Kappa light chain restriction & $11 / 27$ & $41 \%$ \\
\hline Lambda light chain restriction & $9 / 27$ & $33 \%$ \\
\hline unknown & $7 / 27$ & $26 \%$ \\
\hline \multicolumn{3}{|l|}{ Serum Beta-2-microglobulin } \\
\hline Elevated & $5 / 27$ & $18 \%$ \\
\hline Normal & $7 / 27$ & $26 \%$ \\
\hline Unknown & $15 / 27$ & $56 \%$ \\
\hline \multicolumn{3}{|l|}{ Serum protein } \\
\hline Elevated & $3 / 27$ & $11 \%$ \\
\hline Normal & $17 / 27$ & $63 \%$ \\
\hline Low & $3 / 27$ & $11 \%$ \\
\hline Unknown & $4 / 27$ & $15 \%$ \\
\hline \multicolumn{3}{|l|}{ Serum protein immunofixation } \\
\hline Positive & $14 / 27$ & $52 \%$ \\
\hline Negative & $9 / 27$ & $33 \%$ \\
\hline Unknown & $4 / 27$ & $15 \%$ \\
\hline \multicolumn{3}{|l|}{ Serum LDH } \\
\hline Elevated & $12 / 27$ & $44 \%$ \\
\hline Normal & $11 / 27$ & $41 \%$ \\
\hline Unknown & $4 / 27$ & $15 \%$ \\
\hline \multicolumn{3}{|l|}{ Serum calcium } \\
\hline Elevated & $1 / 27$ & $4 \%$ \\
\hline Normal & $21 / 27$ & $78 \%$ \\
\hline Low & $2 / 27$ & $7 \%$ \\
\hline Unknown & $3 / 27$ & $11 \%$ \\
\hline \multicolumn{3}{|l|}{ Prior or adjuvant therapies } \\
\hline $\mathrm{HSCT}$ & $12 / 27$ & $44 \%$ \\
\hline $\mathrm{TBI}$ & $3 / 27$ & $11 \%$ \\
\hline Systemic immunochemotherapy & $14 / 27$ & $52 \%$ \\
\hline
\end{tabular}

$F$ female, $M$ male, Med. median, $L D H$ lactate dehydrogenase, $H S C T$ Hematopoietic stem cell transplantation, $T B /$ total body irradiation 
Table 2 Treatment characteristics for 33 extramedullary plasmocytoma lesions

\begin{tabular}{|c|c|c|}
\hline Characteristic & Value & Percentage/range \\
\hline \multicolumn{3}{|c|}{ Treatment parameters } \\
\hline Med. radiation dose (range), Gy & 45 & $12-55.8$ \\
\hline$\leq 45 \mathrm{~Gy}$ & $18 / 33$ & $55 \%$ \\
\hline$>45 \mathrm{~Gy}$ & $15 / 33$ & $45 \%$ \\
\hline Med. fraction dose (range), Gy & 2 & $1.8-4.0$ \\
\hline Med. treatment time, $d$ & 35 & $4-52$ \\
\hline \multicolumn{3}{|l|}{ Sites of RT } \\
\hline Nasal/paranasal & $10 / 33$ & $30 \%$ \\
\hline Pharynx & $6 / 33$ & $18 \%$ \\
\hline Orbital/epidural & $6 / 33$ & $18 \%$ \\
\hline Cervical & $6 / 33$ & $18 \%$ \\
\hline Cutaneous/muscular & $5 / 33$ & $16 \%$ \\
\hline \multicolumn{3}{|l|}{ Type of RT } \\
\hline Postoperative & $11 / 33$ & $33 \%$ \\
\hline Definitive & $22 / 33$ & $67 \%$ \\
\hline \multicolumn{3}{|l|}{ RT technique } \\
\hline IMRT & $14 / 33$ & $42 \%$ \\
\hline CRT & $19 / 33$ & $58 \%$ \\
\hline \multicolumn{3}{|l|}{ Bone erosion } \\
\hline Yes & $13 / 33$ & $40 \%$ \\
\hline No & $14 / 33$ & $42 \%$ \\
\hline Unknown & $16 / 33$ & $18 \%$ \\
\hline \multicolumn{3}{|l|}{ Local response } \\
\hline Complete response & $14 / 33$ & $43 \%$ \\
\hline Partial response & $11 / 33$ & $33 \%$ \\
\hline Stable & $1 / 33$ & $3 \%$ \\
\hline Progression & $3 / 33$ & $6 \%$ \\
\hline Unknow & $5 / 33$ & $15 \%$ \\
\hline
\end{tabular}

Med median, CRT conventional radiotherapy, CTX chemotherapy, RT radiotherapy, IMRT intensity-modulated radiotherapy

was calculated from the initiation of RT until the time of documented local relapse or death. Time-dependent event curves were calculated using the Kaplan-Meier method and were compared using the log-rank test.

\section{Definition of response}

EMP response was assessed during RT, and at a 3-month follow-up appointment clinically and radiologically. Complete response (CR) was defined as complete clinical regression of irradiated lesion, while partial response (PR) represented any response less than complete that showed $>50 \%$ radiological response. Local progression was defined as $>25 \%$ clinical progress of the lesions.

\section{Results}

The local control (LC) rate for the whole cohort was $76 \%$. In subgroup analysis, the LC rate for primary EMP was $93 \%$ and for the secondary EMP lesions $61 \%(P<$ 0.05). CR after local RT was achieved for $42 \%$ lesions (67\% for primary EMP vs. $22 \%$ for the secondary EMP lesions; $P<0.01$ ). The 2 -year LC rate of $89 \%$ and 5 -year LC rate of $80 \%$ (Fig. 1a). In the whole cohort, the median OS has not been reached with 2-year OS of $72 \%$ and 5 -year OS rate of $55 \%$ (Fig. 1b). The median duration of LC for the entire cohort has not been reached with no noticeable difference between primary and secondary $\operatorname{EMP}(P=9)$. The 2-year LC rate in primary EMP patients was $92 \%$ versus $87 \%$ in secondary EMP $(P$ $=0.9$ ), respectively. The median OS from the time of RT was significantly longer in patients with primary EMP $(P=.035)$. The 2 -year OS rate was $85 \%$ versus $53 \%$, respectively. Only two patients with primary EMP developed relapse outside the radiation fields ( 3 and 8 years after initial radiation course) and were treated successfully with salvage RT to cervical lymph node (36 Gy) and stomach (40 Gy), respectively.

Regarding the radiation dose, the overall response rate (ORR) for the EMP lesions treated with high-dose regimens versus low-dose regimens was $87 \%$ versus $67 \%$ ( $P$ $=0.2$ ), and the $C R$ rate was $53 \%$ versus $33 \%$, respectively $(P=0.3)$. According to site of lesions, the ORR was higher following high-doses in nasal/paranasal ( $83 \%$ vs. $50 \%, P=.3)$, pharyngeal (100\% in both therapy arms), orbital $(100 \%$ vs. $60 \%, P=.7)$, and cervical $(100 \%$ vs. $80 \%$, $P=.8$ ) lesions. While in patients with cutaneo-muscular lesions the ORR was $50 \%$ following high-dose regimens versus $66 \%$ with low-doses $(P=.8)$. In the whole cohort, the median survival with high-dose RT group was significantly longer $(P=0.02)$. The 2 -year OS rate in the entire cohort was $86 \%$ with high-dose group versus $55 \%$ in low-dose group (Fig. 2, $P=0.02$ ). In subgroups analysis, primary EMP patients treated with high-dose RT had a non-significant higher ORR ( $100 \%$ vs. $80 \%$, respectively; $P=0.3)$ and longer duration of $\operatorname{LC}(P=0.3)$ with a longer survival $(P=0.05)$ than patients in low-dose group. On the other hand, no significant difference has been detected in secondary EMP patients treated with high-dose RT regarding ORR (60\% vs. $62 \%$, respectively; $P=1)$, and survival $(P=0.4)$. However, DOLC was longer with low-dose group $(P=0.03)$. The 2-year OS of patients developed CR following RT was $90 \%$ with an platue till 5 years while other patients had 2-year OS of $57 \%$ and 5 -year survival of $37 \%$ (Fig. 3, $P=0.02$ ).

Regarding patients' characteristics listed in Table 1, a non-significant improvement was seen in patients with normal $\beta 2$-microglobulin $(P=0.1)$ and negative immunofixation $(P=0.16)$. While patients with normal lactat dehydrogenase $(\mathrm{LDH}$ value $(P=0.09)$ or negative 

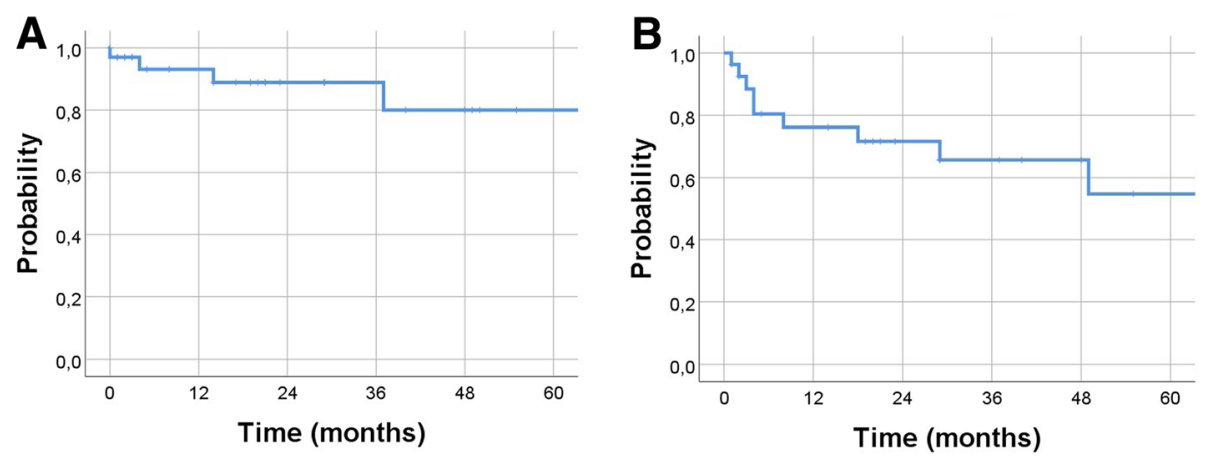

Fig. 1 Kaplan-Meier estimates of local control (a) and overall survival for all patients (b)

immunofixation $(P=0.1)$ may impact the overall survival of EMP patients.

In the whole cohort, there was no LC advantage in patients who underwent surgical resection $(P=0.8)$. In contrast, better OS following postoperative RT in comparison with patients received RT alone has been observed (2-year OS of 89 versus 60\%; $P=0.04$ ), however this benefit couldn't be seen in patients with primary EMP $(P=0.8)$. Bone infiltration or erosion didn't impact LC $(P=0.2)$ or survival $(P=0.4)$ of our patients.

\section{Toxicities}

RT was well tolerated in our cohort without significant adverse events (AE). During the RT courses, almost all patients showed grade 1 toxicity (70\%). Only $15 \%$ of the patients experienced grade 2 AE (29\% with high-dose regimens versus $11 \%$ in low-dose group, $P=0.6$ ). Grade 2 toxicity rate was lower with IMRT technique in comparison with conventional RT technique ( $14 \%$ versus
$33 \%, P=0.3)$. Most common AE were erythema, xerostomia, and mucositis. No moderate or severe radiation-related toxicities. There were three radiation breaks (one primary EMP course and 2 secondary EMP).

\section{Discussion}

The hereby presented study reveals one of the largest study collectives of plasmocytomas in the literature and corroborates the role of RT as a curative treatment for EMP. A local control rate of $76 \%$ could be achieved which is in accordance with the literatur indicating a control rate between $66-100 \%[4,6,7,9,13,20-23]$. Importantly, further sub-stratification revealed a significant favour of primary in comparison to secondary EMP regarding $\mathrm{LC}(93 \%$ vs. $61 \%), \mathrm{CR}$ rate $(67 \%$ vs. $22 \%)$ and 2 -year OS rate of $85 \%$ vs. $53 \%$. Although belonging to the continuum plasma-cell neoplasms altogether, primary and secondary EMP represent distinct entitities with different behaviour. Primary EMP is a localized

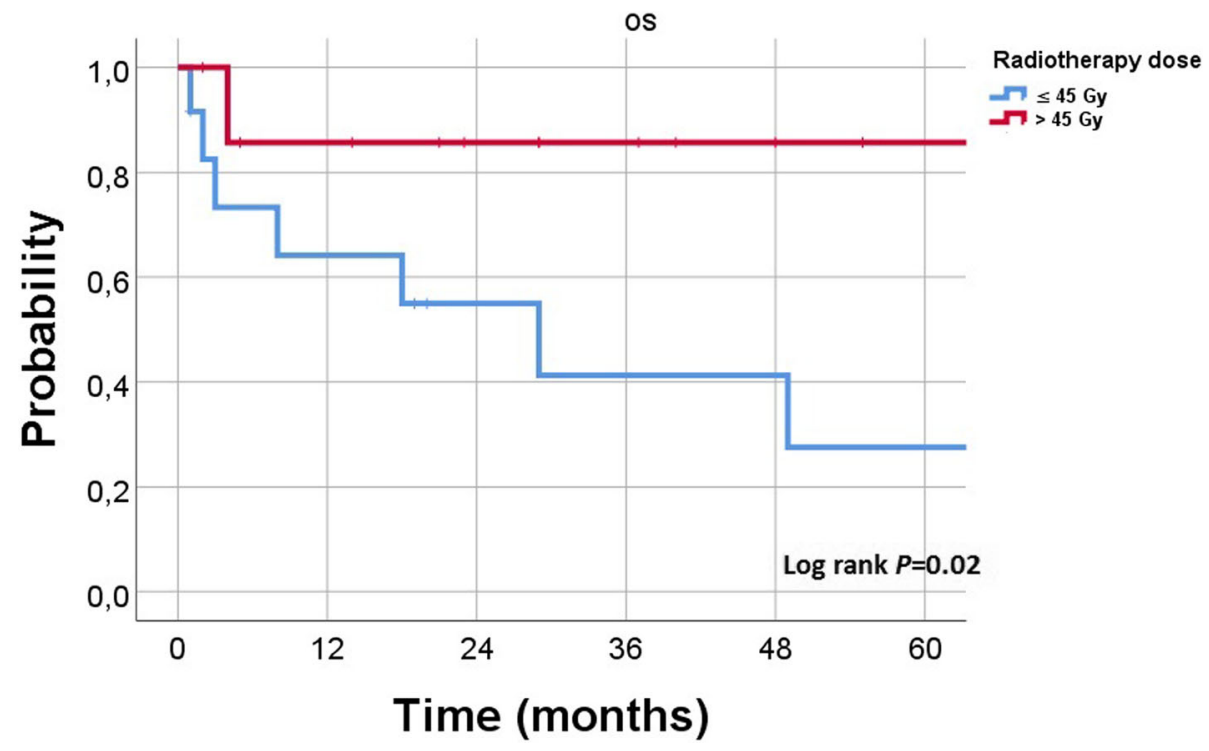

Fig. 2 Kaplan-Meier estimates of overall survival according to radiation dose in all $(N=27)$ patients 


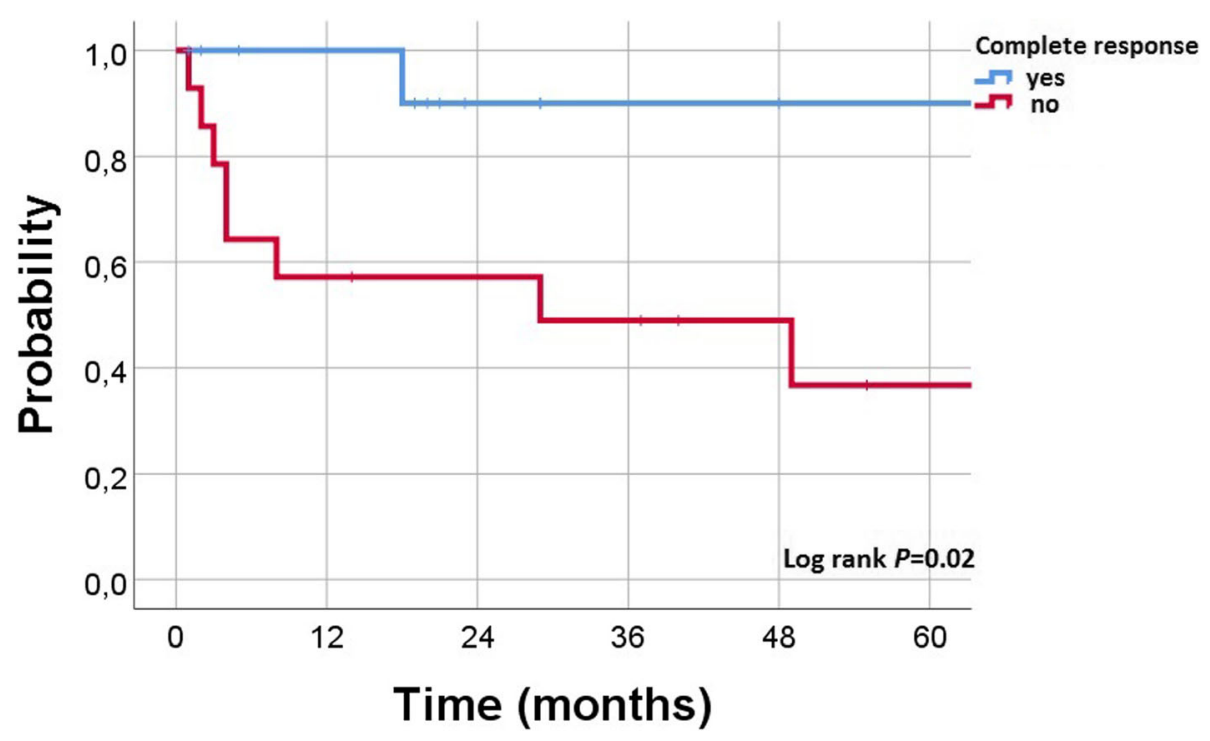

Fig. 3 Kaplan-Meier estimates of overall survival for all patients and according to response after radiotherapy

disease and curable by local RT, while secondary EMP is a systemic disease.

Only a minority of patients with primary EMP progresses to multiple myeloma (4-33\% after several years) $[5,6,9,13,15,20,21,23]$ underlining the localized character for primary EMP. No systemic progress to MM could be seen in the patients of this analysis. Interestingly, most transformations occur within the first 5 years with late disseminations being possible $[6,13,15,21,23]$ . It is tempting to speculate that biologic behaviour of EMP may change during the course of disease with a less aggressive pattern seen in the long-term period.

The present analysis shows a non-significant higher ORR and longer duration of LC with a longer survival for the high-dose group in primary EMP, thus suggesting a clinical benefit of a RT dose above 45 Gy. Defining the adequate radiation dose for EMP has been an issue of debate since several decades leading to the establishment of cutoff-doses.

Various studies postulated cutoff-values between 40 and 49 Gy for improved control or disease-free survival [13, 24-26]. Other analyses often failed to demonstrate a dose-response-relationship or did not provide own insights in dosage $[5-7,27]$. In a meta-analysis including 315 patients, a dose-escalation $>45$ Gy showed improved disease-free survival [23]. Strojan et al. [21] introduced a differentiated approach demanding 40-50 Gy for macroscopic disease (with no local relapse with $>40$ ), whereas adjuvant RT of 36-40 Gy may be adequate. Taken this data into account, the International Lymphoma Radiation Oncology Group (ILROG) has recently provided comprehensive guidelines on the treatment of $\mathrm{MM}$ and EMP recommending a dose between 40 and 50 Gy [17].
One major drawback for dose-definition is the rarity of EMP requiring a patient recrutation of several decades with changes in radiation technique and concepts [21, 25]. Therefore, comparable patient groups concerning dosage could not always be established due to low patient number, biological different RT regimes (split course, hypofractionation) or limited dose ranges/variation $[21,24,25]$. The present analysis is one of the first to introduce a systematic comparison of nearly equivalent RT dose groups and elaborates the differences. A potential bias concerning RT location and subsequent dose adaption did not show a significant impact, probably due to small sample size .

Furthermore, there has been considerable debate on the elective regional lymph nodes irradiation, although a minority of EMP reveals lymph-node involvement in up to one third of cases $[9,28]$. Following initial therapy, locoregional recurrences are rare events $[6,9,13,20,28]$ and may be re-irradiated effectively [9]. The ILROG guidelines renounce an inclusion of lymph node except for bulky disease and tumor adjacent regional lymph-nodes permitting an inclusion within the PTV without a relevant increase in radiation toxicity [17]. Consistently, only $6 / 33$ patients $(18 \%)$ received elective nodal RT. Novel systemic therapies following RT may improve outcome [29].

To further characterize clinical risk factors, the serological profile before RT was analysed for each patient regarding hemoglobin level, serum calcium, serum protein, immunfixation in urin and serum, ß2-microglobulin, LDH. Positive immunfixation, although nonsignificant, may have a worse impact on LC and OS in the present collective, which is debatable in 
the literature: while some research group identified positive serum protein as a factor heralding progression to MM [27], others negate a significant impact [6, 7].

Within the last years, the chromosomal and molecular analysis of pathogenesis could shed light on the development MM and helped to identify "key players" such as immunoglobulin heavy-chain translocations, cyclin D overexpression or trisomies [30]. Thus, the established international staging system defining risk categories via serum albumin and $\beta 2$-microglobulin levels may be further stratified on the molecular level c [30,31].

Our study bears some limitations known to retrospective analysis as the lack of a control group or different treatment group. Furthermore, the number of patients is limited due to the low incidence of the disease which may hamper statistical analysis. In addition by focussing on head and neck plasmocytoma for their predominance in EMP, tumors of other location with possible differentiated biology and response have been excluded.

The optimal radiation dose for EMP warrants further investigations. More clinical and biological data are needed to identify patients who may require neoadjuvant or adjuvant therapies, as well as dose escalation during RT as part of a biologically guided therapeutic strategy. Additionaly, the benefit of a combined modality treatment of RT and proteasome-inhibitor or immunomodulatory agents remain uncertain and may be warranted for patients with incomplete response RT. Currently, a multi-center study is under way to enable a more profound understanding of EMP and its optimal treatment approach.

\section{Conclusion}

Patients with primary EMP manifestations are associated with better outcome compared with secondary EMP. Response to RT might influence the OS of EMP patients. A radiation dose $\leq 45$ Gy confer a comparable CR rate to high-dose regimens and appears to be an effective treatment for controlling EMP progression. Radiation dose-escalation seems to be beneficial for particular subgroups of patients. Further studies with a larger sample size are needed to confirm the results of this analysis.

\footnotetext{
Abbreviations

DOLC: Duration of local control; EFS: Event-free survival; EMP: Extramedullary plasmacytoma; LC: Local control; MM: Multiple myeloma; OS: Overall survival; RT: Radiotherapy
}

\section{Acknowledgements}

Not applicable.

Funding

Not applicable.

Availability of data and materials

Please contact author for data requests.

\section{Authors' contributions}

$\mathrm{MO}$ and KE was involved in formal analysis, research methodology and first manuscript drafting. All co-authors were involved in conceptualization of manuscript, and manuscript drafting and editing. HTE was the senior author who oversaw the project. All co-authors read and approved the final manuscript.

\section{Ethics approval and consent to participate}

Patients signed consent prior to treatment being initiated and data being collected.

All procedures performed in studies involving human participants were in accordance with the ethical standards of the institutional and/or national research committee and with the 1964 Helsinki declaration and its later amendments or comparable ethical standards. For this type of study formal consent is not required.

\section{Consent for publication}

Patients signed consent prior to treatment being initiated and data being collected.

\section{Competing interests}

The authors declare that they have no competing interests.

\section{Publisher's Note}

Springer Nature remains neutral with regard to jurisdictional claims in published maps and institutional affiliations.

\section{Author details}

${ }^{1}$ Department of Radiation Oncology, University Hospital of Muenster, Albert-Schweitzer-Campus 1, Building A1, 48149 Muenster, Germany. ${ }^{2}$ Department of Otorhinolaryngology, Head and Neck Surgery, University Hospital of Muenster, Muenster, Germany. ${ }^{3}$ Department of Internal Medicine-A (Hematology, Oncology, Hemostaseology and Pulmonology), University Hospital Muenster, Muenster, Germany.

Received: 19 November 2018 Accepted: 28 March 2019

Published online: 15 April 2019

\section{References}

1. Swerdlow SH, editor. WHO classification of tumours of haematopoietic and lymphoid tissues. 4th ed. Lyon: International Agency for Research on Cancer; 2017

2. Alexiou C, Kau RJ, Dietzfelbinger H, Kremer M, Spiess JC, Schratzenstaller B, Arnold W. Extramedullary plasmacytoma: tumor occurrence and therapeutic concepts. Cancer. 1999;85:2305-14.

3. Soutar R, Lucraft H, Jackson G, Reece A, Bird J, Low E, Samson D. Guidelines on the diagnosis and management of solitary plasmacytoma of bone and solitary extramedullary plasmacytoma. Clin Oncol (R Coll Radiol). 2004;16: 405-13

4. Barzenje DA, Kolstad A, Ghanima W, Holte H. Long-term outcome of patients with solitary plasmacytoma treated with radiotherapy: a population-based, single-center study with median follow-up of 13.7 years. Hematol Oncol. 2018;36:217-23. https://doi.org/10.1002/hon.2415.

5. Knowling MA, Harwood AR, Bergsagel DE. Comparison of extramedullary plasmacytomas with solitary and multiple plasma cell tumors of bone. JCO. 1983;1:255-62. https://doi.org/10.1200/JCO.1983.1.4.255.

6. Brinch L, Hannisdal E, Abrahamsen AF, Kvaløy S, Langholm R. Extramedullary plasmacytomas and solitary plasma cell tumours of bone. Eur J Haematol. 1990:44:132-5.

7. Soesan M, Paccagnella A, Chiarion-Sileni V, Salvagno L, Fornasiero A, Sotti G, et al. Extramedullary plasmacytoma: clinical behaviour and response to treatment. Ann Oncol. 1992;3:51-7.

8. Simon W, Schneppenheim P, Fendel H. The extraosseous plasmacytoma involvement of both breasts. Rofo. 1994;161:471-2. https://doi.org/10.1055/ s-2008-1032571

9. Shih LY, Dunn P, Leung WM, Chen WJ, Wang PN. Localised plasmacytomas in Taiwan: comparison between extramedullary plasmacytoma and solitary plasmacytoma of bone. Br J Cancer. 1995;71:128-33.

10. Sato K, Fumimoto S, Fukada T, Ichihashi Y, Ochi K, Satomi H, et al. Extramedullary Plasmacytoma arising from the anterior mediastinum. Ann Thorac Surg. 2017;103:e393-5. https://doi.org/10.1016/j.athoracsur.2016.10.064. 
11. Ames J, Al-Samaraee A, Takahashi T. Extraosseous multiple myeloma: case report of presentation in the lower extremity soft tissues with literature review. Case Rep Radiol. 2017;2017:1-9. https://doi.org/10.1155/2017/ 9159035.

12. Krause S, Hillengass J, Goldschmidt H, Debus J, Neuhof D. Radiotherapy of solitary plasmacytoma. Ann Hematol. 2011;90:1093-7. https://doi.org/10. 1007/s00277-011-1190-7.

13. Creach KM, Foote RL, Neben-Wittich MA, Kyle RA. Radiotherapy for extramedullary Plasmacytoma of the head and neck. Int J Radiat Oncol Biol Phys. 2009;73:789-94. https://doi.org/10.1016/j.jirobp.2008.04.077.

14. Galieni P, Cavo M, Pulsoni A, Avvisati G, Bigazzi C, Neri S, et al. Clinical outcome of extramedullary plasmacytoma. Haematologica. 2000;85:47-51.

15. D'Aguillo C, Soni RS, Gordhan C, Liu JK, Baredes S, Eloy JA. Sinonasal extramedullary plasmacytoma: a systematic review of 175 patients. Int Forum Allergy Rhinol. 2014;4:156-63. https://doi.org/10.1002/alr.21254.

16. Na'ara S, Amit M, Gil Z, Billan S. Plasmacytoma of the Skull Base: a metaanalysis. J Neurol Surg B. 2016;77:61-5. https://doi.org/10.1055/s-00351560047.

17. Tsang RW, Campbell BA, Goda JS, Kelsey CR, Kirova YM, Parikh RR, et al. Radiation therapy for solitary Plasmacytoma and multiple myeloma: guidelines from the international lymphoma radiation oncology group. Int J Radiat Oncol Biol Phys. 2018;101:794-808. https://doi.org/10.1016/j.jjrobp. 2018.05.009.

18. Hoskin PJ, Kirkwood AA, Popova B, Smith P, Robinson M, Gallop-Evans E, et al. 4 Gy versus $24 \mathrm{~Gy}$ radiotherapy for patients with indolent lymphoma (FORT): a randomised phase 3 non-inferiority trial. Lancet Oncol. 2014;15: 457-63. https://doi.org/10.1016/S1470-2045(14)70036-1.

19. König L, Stade R, Rieber J, Debus J, Herfarth K. Radiotherapy of indolent orbital lymphomas. Strahlenther Onkol. 2016;192:414-21. https://doi.org/10. 1007/s00066-016-0962-3.

20. Bolek TW, Marcus RB, Mendenhall NP. Solitary plasmacytoma of bone and soft tissue. Int J Radiat Oncol Biol Phys. 1996;36:329-33. https://doi.org/10. 1016/S0360-3016(96)00334-3.

21. Strojan P, Šoba E, Lamovec J, Munda A. Extramedullary plasmacytoma: clinical and histopathologic study. Int J Radiat Oncol Biol Phys. 2002;53:692701. https://doi.org/10.1016/S0360-3016(02)02780-3.

22. Tsang RW, Gospodarowicz MK, Pintilie M, Bezjak A, Wells W, Hodgson DC, Stewart AK. Solitary plasmacytoma treated with radiotherapy: impact of tumor size on outcome. Int J Radiat Oncol Biol Phys. 2001;50:113-20.

23. Venkatesulu B, Mallick S, Giridhar $P$, et al. Pattern of care and impact of prognostic factors on the outcome of head and neck extramedullary plasmacytoma: a systematic review and individual patient data analysis of 315 cases. Eur Arch Otorhinolaryngol. 2018;275:595-606. https://doi.org/10 1007/s00405-017-4817-z.

24. Mendenhall CM, Thar TL, Million RR. Solitary plasmacytoma of bone and soft tissue. Int J Radiat Oncol Biol Phys. 1980;6:1497-501.

25. Tournier-Rangeard L, Lapeyre M, Graff-Caillaud P, Mege A, Dolivet G, Toussaint B, et al. Radiotherapy for solitary extramedullary plasmacytoma in the head-and-neck region: a dose greater than 45 Gy to the target volume improves the local control. Int J Radiat Oncol Biol Phys. 2006;64:1013-7. https://doi.org/10.1016/j.jijrobp.2005.09.019.

26. Petit C, Mazeron R, Boros A, Rivera S, Blanchard P, Deutsch E. EP-1245: a systematic review of dose-effect relationship in radiotherapy for head and neck plasmacytoma. Radiother Oncol. 2018;127:S688-9. https://doi.org/10. 1016/S0167-8140(18)31555-X.

27. Reed V, Shah J, Medeiros $\sqcup$, Ha CS, Mazloom A, Weber DM, et al. Solitary plasmacytomas. Cancer. 2011;117:4468-74. https://doi.org/10.1002/cncr.26031.

28. Liebross RH, Ha CS, Cox JD, Weber D, Delasalle K, Alexanian R. Clinical course of solitary extramedullary plasmacytoma. Radiother Oncol. 1999;52: 245-9.

29. Le Ray E, Belin L, Plancher C, Anract P, Babinet A, Dumaine V, et al. Our experience of solitary plasmacytoma of the bone: improved PFS with a short-course treatment by IMiDs or proteasome inhibitors combined with intensity-modulated radiotherapy. Leuk Lymphoma. 2018;59:1756-8. https:// doi.org/10.1080/10428194.2017.1393667.

30. Chesi M, Bergsagel PL. Molecular pathogenesis of multiple myeloma: basic and clinical updates. Int J Hematol. 2013;97:313-23. https://doi.org/10.1007/ s12185-013-1291-2.

31. Greipp PR, Miguel JS, Durie BGM, Crowley JJ, Barlogie B, Bladé J, et al. International staging system for multiple myeloma. JCO. 2005;23:3412-20. https://doi.org/10.1200/JCO.2005.04.242.
32. Elsayad K, Kriz J, Moustakis C, Scobioala S, Reinartz G, Haverkamp U, Willich N, Weishaupt C, Stadler R, Sunderkötter C, Eich HT. Total Skin Electron Beam for Primary Cutaneous T-cell Lymphoma. Int J Radiat Oncol Biol Phys. 2015; 93(5):1077-86.

33. Oertel M, Elsayad K, Haverkamp U, Stelljes M, Eich HT. Radiotherapy for extramedullary leukaemic manifestation (Chloroma). Strahlenther Onkol. 2018;194(2):164-73. https://doi.org/10.1007/s00066-017-1236-4.

34. Kroeger K, Elsayad K, Moustakis C, Haverkamp U, Eich HT. Low-dose total skin electron beam therapy for cutaneous lymphoma : Minimal risk of acute toxicities. Strahlenther Onkol. 2017;193(12):1024-30. https://doi.org/10.1007/ s00066-017-1188-8.

\section{Ready to submit your research? Choose BMC and benefit from:}

- fast, convenient online submission

- thorough peer review by experienced researchers in your field

- rapid publication on acceptance

- support for research data, including large and complex data types

- gold Open Access which fosters wider collaboration and increased citations

- maximum visibility for your research: over $100 \mathrm{M}$ website views per year

At BMC, research is always in progress.

Learn more biomedcentral.com/submissions 